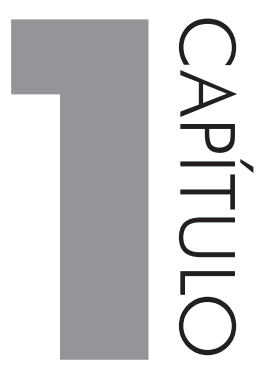

\title{
TEMPO SOCIAL E TEMPO COGNITIVO NO ENVELHECIMENTO
}

Os efeitos do envelhecimento da população já vêm sendo observados em todo o mundo, inclusive no Brasil. A partir do que apontam os dados do Censo 2010 do Instituto Brasileiro de Geografia e Estatística (IBGE), no ano 2025, a população de idosos do Brasil será superior a $16 \%$, o que colocará o Brasil em quinto lugar no ranking mundial de países com maior população de idosos. ${ }^{1}$ Segundo as estimativas do IBGE, em 2060, o Brasil passará a ter 58,4 milhões de idosos, correspondendo a $26,7 \%$ do total da população. O país contabiliza hoje mais de 3,5 milhões de idosos com idade superior a 80 anos. Em 2060, esse público será de 19 milhões, o que corresponde a um crescimento equivalente a 27 vezes em relação a 1980, quando o país possuía menos de 1 milhão de pessoas nessa faixa etária: 684.789 de pessoas (IBGE, 2010).

1 De acordo com a legislação vigente, e adotada nas previsões do IBGE, considera-se como idosa a pessoa de 60 anos de idade. 


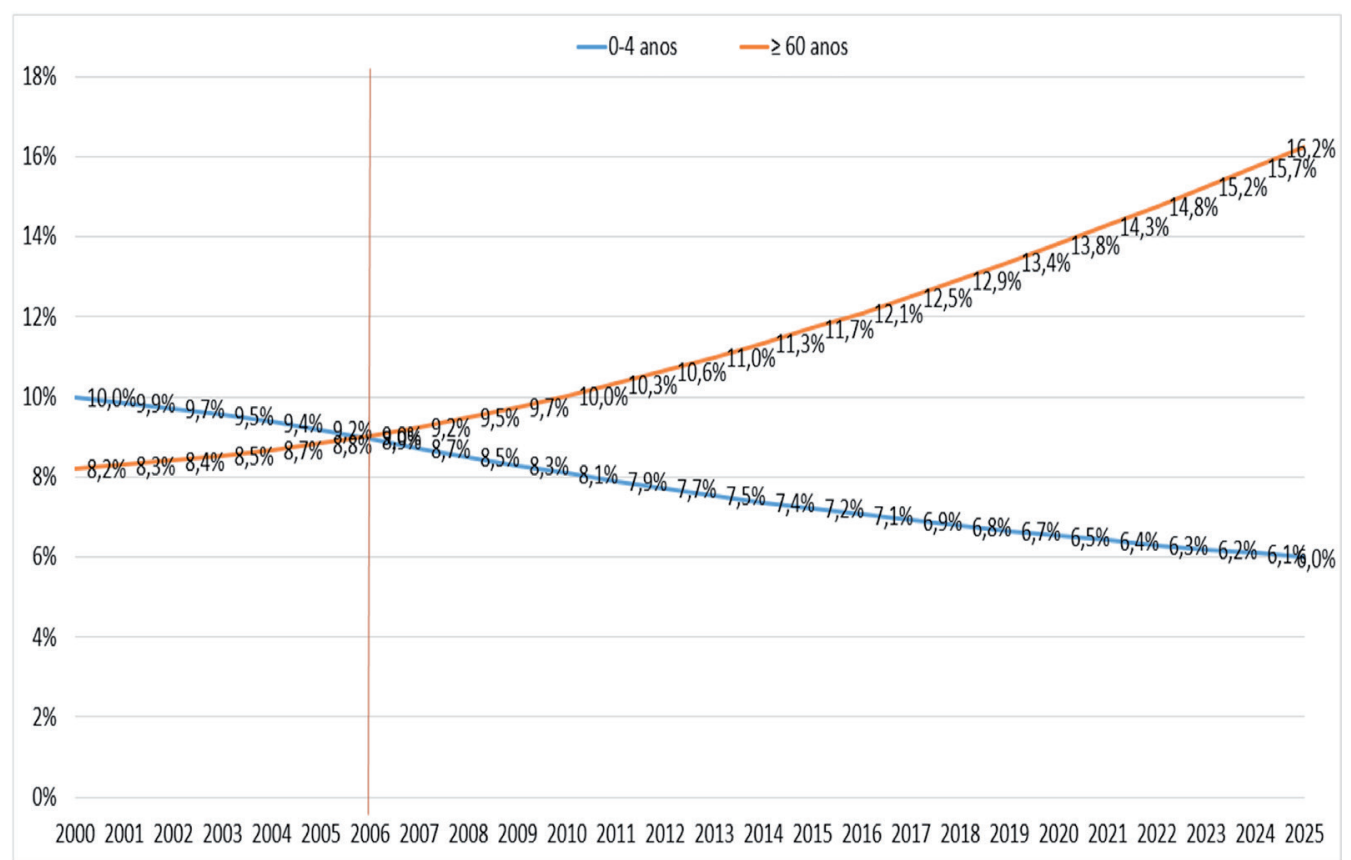

Gráfico 1 Progressão da população brasileira 2000-2025

Fonte: Elaborado pela autora.

A mudança da composição demográfica brasileira vai alterar profundamente as relações educacionais. Em 2025, segundo as previsões do IBGE, haverá mais idosos do que crianças.

A situação brasileira na relação com o fenômeno do envelhecimento convive, passo a passo, com a realidade de um país ainda considerado jovem. A inversão da pirâmide populacional pega de surpresa toda uma estrutura socioeconômica e política que, sequer, é habilitada a atender as questões das outras faixas etárias, muito embora a enfrentar as demandas de um fenômeno social chamada "velhice ou envelhecimento populacional". (SILVA, 2016, p. 113)

Assim, ante a longevidade da população, políticas públicas precisam garantir qualidade de vida a esse grupo de pessoas. Para qualidade de vida, adotamos o conceito do Grupo de Qualidade de Vida da Organização Mundial de Saúde (World Health Organization Quality of Life Group), segundo o qual a qualidade de vida se refere à percepção do indivíduo em relação a sua posição na vida, no contexto da cultura e no sistema de valores em que vive, bem como a seus objetivos, expectativas, padrões e preocupações (THE WHOQOL GROUP, 1998). 
Adotamos, para o escopo deste trabalho, a terminologia "envelhescente" (com SC, assim como nascer, crescer), que corresponde à pessoa entre as faixas etárias de 45 a 59 anos. Ao utilizarmos a palavra envelhescente, assumimos a postura de Mendes (2012), que inicialmente identificou o emprego da palavra para aquelas pessoas que estavam abertas a novos aprendizados.

Faz-se necessário, então, pensar em estratégias que garantam uma melhor qualidade de vida ao brasileiro, cuja expectativa de vida passará de 75 anos para 81 anos de idade, segundo projeção do IBGE. Nossa proposta de ensino de inglês visa a contribuir para a qualidade de vida desse público. Para isso, precisamos lidar com a noção de tempo que está presente no processo de envelhecimento.

Os envelhescentes e pessoas da terceira idade de hoje desejam ressignificar suas vidas, com atividades diferentes, dentre elas o aprendizado de uma língua estrangeira, como o inglês. Isso significa que os cursos de formação de professores precisam se preparar para um novo nicho no mercado de trabalho: envelhescentes e terceira idade.

Na cultura ocidental, tempo está associado à sucessão dos anos, dias, horas. $\mathrm{O}$ quantitativo de anos vividos por uma pessoa faz com que se insira numa determinada fase da vida: criança, adolescente, adulto, envelhescente, terceira idade.

As mudanças que se processam na pessoa no decorrer da passagem do tempo não estão associadas apenas a aspectos biológicos. Condições socioeconômicas podem, por exemplo, favorecer o retardamento ou adiantamento dos traços de sua aparência, sendo esse processo gradativo para uns e mais rápido para outros, a depender de sua forma de vida. No plano biológico, as mudanças decorrem de transformações fisiológicas. Assim, com a chegada da idade, surgem carência de acuidade visual, cabelos grisalhos, ritmo de marcha mais lenta, etc. Esses aspectos interferem psiquicamente nas dimensões cognitiva, psicológica e social do idoso (CAETANO, 2006).

Como o aprendizado de uma língua estrangeira interfere na percepção e nas emoções das pessoas, propomos lidar com duas dimensões do tempo, que estão relacionadas ao processo do envelhecimento e que podem interferir no processo de ensino-aprendizagem de uma língua, como o inglês: o tempo cognitivo e o tempo social. Por tempo cognitivo, estamos entendendo as relações estabelecidas pela cognição e sua demanda de tempo, a exemplo do tempo de processamento da leitura e do tempo de execução de um exercício ou de uma atividade. Como, com o envelhecimento, chegam as perdas cognitivas, é preciso identificar qual é a interferência dessas perdas no processo de ensino-aprendizagem de uma outra língua.

O tempo pode também estar relacionado ao momento ou ocasião apropriada para a realização de uma ação (o tempo da aposentadoria, o tempo de um novo aprendizado), o que caracteriza o que chamamos de tempo social. Em um curso de 
língua inglesa para o público de envelhescentes e pessoas da terceira idade, os efeitos do tempo social são diferentes do que seria para alunos regulares da educação básica: motivações para a aprendizagem de uma língua estrangeira, como a língua inglesa, ou o estado emocional durante as aulas não são os mesmos. Por isso, é importante conhecer as dimensões do tempo social e do tempo cognitivo no envelhecimento que precisam ser consideradas no ensino de uma língua estrangeira.

\subsection{TEMPO SOCIAL}

A consciência sobre o envelhecimento muda padrões sociais. No passado, pessoas da terceira idade deixavam de ter uma vida social, ficando mais em casa, cuidando dos netos, ajudando as famílias, e se anulavam com relação à sua própria identidade. Hoje, já não vemos mais esse comportamento de maneira tão generalizada. As pessoas da terceira idade desejam viver de forma diferente, fazendo coisas diferentes que nunca tiveram a oportunidade de fazer. Essas mudanças de comportamento levam a mudanças nos rótulos associados a esse público. Expectativas e motivações em relação à escolarização e ao mercado de trabalho podem interferir no processo de ensino-aprendizagem de uma língua estrangeira.

\subsubsection{Do velho ao idoso}

O ciclo da vida do ser humanos costuma ser dividido em quatro etapas ou fases: infância, adolescência, adultez e velhice ou terceira idade. A Organização Mundial da Saúde (OMS) vem considerando a idade de 60 anos como o início da terceira idade. Do ponto de vista biológico, essa idade corresponde à fase da vida em que traços de senilidade começam a ficar aparentes (HADDAD, 1997).

Adotado recentemente no Brasil, o termo "terceira idade" foi trazido por gerontologistas que se formaram na França (DEBERT, 1994). Segundo Haddad (1986), a designação "terceira idade", inicialmente, foi utilizada pelo gerontologista francês Heut, que a conceituou como a fase mais madura da vida que se inicia próximo à idade da aposentadoria. Contudo, a faixa de idade que compreende a terceira idade (troisième áge) não é ponto pacífico entre os estudiosos: o assunto tem sido bastante discutido por psicólogos, geriatras, gerontologistas, educadores e sociólogos.

O uso de palavras para se referir às fases da vida é modificado com o passar do tempo e com as mudanças da sociedade. Velho, idoso, envelhescente, melhor idade, maior idade, terceira idade são termos que costumam ser utilizados para se referir a mesma fase da vida. Diversos autores se preocuparam com essa questão. Mendes (2012), até início dos anos 1990, categorizava as fases da vida humana em infância (até 11 anos), adolescência (dos 12 aos 19 anos), idade adulta (dos 20 aos 59 anos) e velhice (a partir dos 60 anos). Ao reconhecer que 
o envelhecimento é um processo contínuo, pesquisadores, particularmente da área da psicologia, mais precisamente da psicanálise, foram constituindo uma nova categoria: a envelhescência. Essa fase vai dos 45 aos 59 anos, entretanto, por essa demarcação cronológica não poder ser estanque e precisa, pode perdurar por mais tempo. Prata (2007) caracteriza a envelhescência como

uma preparação para entrar na velhice, assim como a adolescência é uma preparação para a maturidade. Engana-se quem acha que o homem maduro fica velho de repente, assim da noite para o dia. Não. Antes, há envelhescência. E, se você está em plena envelhescência, já notou como ela é parecida com a adolescência. Coloque os óculos e veja como este nosso estágio é maravilhoso: [...] Os adolescentes mudam a voz. Nós envelhescentes, também. Mudamos o nosso ritmo de falar, o nosso timbre. [...] Ninguém entende os adolescentes...Ninguém entende os envelhescentes... Ambos são irritadiços, se enervam com pouco. Acham que já sabem de tudo e não querem palpites nas suas vidas. [...] Os adolescentes não entendem os adultos e acham que ninguém os entende. Nós envelhescentes também não entendemos eles. Ninguém me entende é uma frase típica de envelhescentes. [...] O adolescente ama assistir a um show de um artista envelhescente (Caetano, Chico, Mick Jagger). O envelhescente ama assistir a um show de um artista adolescente [...] Daqui a alguns anos, quando insistirmos em não sair da envelhescência para entrar na velhice, vão dizer: - É um eterno envelhescente! (PRATA, 2007, p. 60-61)

Conforme Mendes (2012), o termo envelhescente é empregado para aquelas pessoas que estão abertos a novos aprendizados, conceito com o qual concordamos e o adotamos. Enquanto a envelhescência abrange as idades de 45 aos 59 anos, a terceira idade é a etapa da vida que começa aos 60. Entretanto, essa não é uma classificação consensual, principalmente quando são levados em conta aspectos sociais e de desenvolvimento humano.

Para Mendes (2012), as fases da vida são cinco (Quadro 1):

Quadro 1 Fases da vida segundo Mendes (2012)

\begin{tabular}{|c|l|}
\hline Infância (0-11 anos) & $\begin{array}{l}\text { Fase inicial da educação e instrução. A criança inicia o processo de saber se } \\
\text { comportar entre as várias categorias da sociedade. }\end{array}$ \\
\hline Adolescência (12-19 anos) & $\begin{array}{l}\text { Fase das descobertas e sentido da vida escolar e início na participação da } \\
\text { sociedade. }\end{array}$ \\
\hline Adoleduto (20-30 anos) & Fase da idade da força de trabalho, etapa vital de dedicação ao trabalho. \\
\hline Adulto (31-44 anos) & Fase de idade posterior à adolescência, fase de transição. \\
\hline Envelhescente (45-59 anos) & Fase de preparação para o sujeito entrar na maturidade, ou velhice. \\
\hline Terceira idade (+ 60 anos) & Fase que pode delongar mais tempo, por não existir uma cronologia precisa. \\
\hline
\end{tabular}


Mendes (2012, p. 59) aponta a predisposição para a discriminação ao se usarem as terminologias "idoso" (ido: aquele que já foi?) e "velho" (fora de prazo de validade?), bem como "terceira e melhor idade", por parte de pessoas envelhescentes, por não aceitarem estar incluídas nessa categoria.

Já Pontarolo e Oliveira (2008), ao considerar os efeitos da longevidade na população, apresentam uma classificação das fases da vida mais ampliada em relação à proposta por Mendes (2012) (Quadro 2):

Quadro 2 Fases da vida, segundo Pontarolo e Oliveira (2008)

\begin{tabular}{|c|l|}
\hline Primeira idade (0-20 anos) & $\begin{array}{l}\text { Fase inicial da educação e instrução. A criança inicia o processo de saber se } \\
\text { comportar entre as várias categorias da sociedade. }\end{array}$ \\
\hline Segunda idade (21-49 anos) & Fase da idade da força de trabalho, etapa vital de dedicação ao trabalho. \\
\hline Terceira idade (50-77 anos) & Fase de preparação para o sujeito entrar na maturidade, ou velhice. \\
\hline Quarta idade (78-105 anos) & $\begin{array}{l}\text { Fase que pode delongar mais tempo. A longevidade será favorecida aos sujei- } \\
\text { tos que souberem adquirir manutenção pessoal. }\end{array}$ \\
\hline
\end{tabular}

Silva (2015) afirma não existir como determinar a idade específica para definir que uma pessoa está na terceira idade. Afirma ainda que, para alguns autores, a terceira idade começa a partir de 60 anos; para outros, a partir de 55 anos. Silva (2015) destaca que já se ensaia a referência a uma quinta idade, iniciada a partir dos 85 anos (Quadro 3):

Quadro 3 Fases da vida segundo Silva (2015)

\begin{tabular}{|c|l|}
\hline Primeira idade (0-20 anos) & $\begin{array}{l}\text { Fase inicial da educação e instrução. A criança inicia o processo de saber } \\
\text { se comportar entre as várias categorias da sociedade. }\end{array}$ \\
\hline Segunda idade (21-54 anos) & Fase da idade da força de trabalho, etapa vital de dedicação ao trabalho. \\
\hline Terceira idade & Fase da terceira idade, a partir de 55 ou 60 anos. \\
\hline Quarta idade (61-84 anos) & Fase da idade da maturidade e preparação para a longevidade. \\
\hline Quinta idade (a partir dos $\mathbf{8 5}$ anos) & $\begin{array}{l}\text { Fase que pode delongar mais tempo. A longevidade será favorecida aos } \\
\text { sujeitos que souberem adquirir manutenção pessoal. }\end{array}$ \\
\hline
\end{tabular}

Na proposta de fases da vida, vale ressaltar que a comparação entre juventude e velhice serve apenas para reconhecer características próprias de determinada fase, uma vez que o envelhecimento não é igual para todos e, a depender de 
características genéticas, culturais e sociais, pode haver algum declínio cognitivo (SANTOS; ROSSETTI; ORTEGA, 2006). Como pudemos observar, não há uma padronização etária para definir se a pessoa é idosa. Considerando a faixa etária, pode ir dos 45 aos 65 anos. Entretanto, aspectos socioculturais podem variar de pessoa para pessoa e isso interfere no estilo de vida, o que permite o surgimento de "estereótipos positivos" como o idoso jovem, o idoso produtivo, o idoso culto e participativo socialmente.

No século XIX, o velho foi condenado ao ostracismo social. O estereótipo de improdutivo o colocava a parte de pessoas de outras faixas etárias. Requeria-se, então, que houvesse o seu amparo por parte da previdência. Já no século XX, o velho foi redefinido socialmente como sujeito da terceira idade, definição essa que permanece até os dias atuais: "o velho, em meio a esses fenômenos sócio-históricos, transformou-se em idoso, um tipo de categorização dos indivíduos de mais idade mais adequada para o sistema social e cultural vigente" (COSTA LIMA, 2014, p. 43).

De acordo com Peixoto (1998), o conceito de idoso foi utilizado para pessoas que viessem a atingir a idade de 60 anos por serem mais "sérios" em sua aparência, enquanto que terceira idade era utilizada para "jovens velhos", aqueles que eram dinâmicos, com uma aparência extrovertida, fácil de interagir com outros grupos. Ainda segundo Peixoto (1998), o idoso simboliza os "velhos respeitados", enquanto terceira idade, os jovens velhos aposentados, dinâmicos, capazes de passar por uma nova etapa da vida. Já Neri e Freire (2000) consideram que a palavra velho ou idoso designa pessoas idosas, que estão na velhice, que estão na última fase do ciclo da vida.

Como vimos, inúmeras são as denominações para as faixas etárias que começam a partir da envelhescência, não sendo necessário se prender a uma idade específica que caracterize a terceira idade ou a velhice. Cabe a cada um decidir que denominação ou conceito utilizar. O que importa é respeitar o padrão e limites individuais para vencer os desafios que chegam com a idade. No entanto, para este trabalho, precisamos estabelecer um recorte, a fim de viabilizar a implementação de uma metodologia. Assim, ainda que reconheçamos que o envelhecimento é um processo, sem necessariamente estar preso a uma faixa etária, consideramos "envelhescentes" as pessoas que estão na faixa etária de 45 a 60 anos e terceira idade as pessoas que ultrapassem os 60.

Independentemente da terminologia, nessa fase da vida, envelhescentes e pessoas da terceira idade desejam continuar ativos para manter o estado biológico em perfeita atividade a fim de ter uma boa saúde e de viver longevamente (NERI; FREIRE, 2000). 


\subsubsection{Envelhescentes e pessoas da terceira idade na atualidade}

Do ponto de vista do tempo cronológico, leva-se muito tempo para se adquirir instrução e ocupação no mercado de trabalho sob as leis vigentes de cada época. O tempo social demonstra como o idoso do passado reagia à vida social, a exemplo de sua reclusão com a chegada da aposentadoria após longos anos de atividade no mercado de trabalho. Ele se restringia a viver em casa, com poucos amigos e pouco relacionamento familiar, diferentemente do idoso atual, que é consciente de que precisa se manter ativo socialmente e cognitivamente. Todo aquele que trabalha ao longo da vida não pode parar e simplesmente se excluir de uma vida social. Afinal, o homem é um ser que vive em sociedade.

Somos o produto de uma experiência de vida compartilhada com nossos familiares. A nossa identidade retrata no futuro o que fomos no passado, o que somos no presente e como pretendemos ser no futuro. Como vimos, no passado, pessoas da terceira idade modificavam sua maneira de viver. Deixavam de ter uma vida social, ficando mais em casa, cuidando dos netos, ajudando as famílias e se anulavam com relação a sua própria identidade. Hoje, essa atitude não é mais apreciada. Esse público deseja aprender a viver de forma diferente, fazendo coisas diferentes que eles nunca tiveram a oportunidade de fazer. A consciência e a mídia ajudam a divulgar a importância de se viver uma nova vida com hábitos mais saudáveis do que eles levavam anteriormente. (MENDES, 2012)

As relações entre terceira idade e outras idades, na sociedade atual, têm sido discutidas no que diz respeito à terminologia idoso, a partir do que se criam estereótipos e crenças sobre como as pessoas se referem aos demais nessa fase da vida. Vieira e Lima (2015) mostram uma dicotomia que avalia positivamente quando tratados individualmente e negativamente quando estão em grupos, ou seja, em sociedade. Esses resultados mostram que as famílias ainda não se preparam para o envelhecimento, não só no que se refere às relações familiares, mas também no que se refere a uma vida futura saudável e suficiente economicamente. Não havendo esse planejamento, podem surgir problemas como declínio mental e ou fisiológico e perdas cognitivas no âmbito individual. No âmbito social, podem surgir o isolamento, a agressividade, etc.

Segundo Frange (2015), nas décadas de 1980 e 1990, já se pôde perceber uma mudança substancial, pois os "idosos" começaram a ser conclamados a adquirir valores mais modernos, como participação social, segurança, autoestima, tudo isso através da compra de utensílios e serviços bancários. Essa tendência de considerar os idosos como consumidores potenciais foi mantida na virada do milênio. Goldstein (1995) mostra que a maioria dos envelhescentes e pessoas da terceira idade apresentam opiniões positivas sobre a vida atual e as possibilidades 
do envelhecimento. Afirma ainda que "os adultos e terceira idade têm, em virtude das mudanças físicas, psicológicas e sociais comuns à sua faixa etária, maior possibilidade de enfrentar tipos de eventos diferentes daqueles enfrentados pelos mais jovens" (GOLDSTEIN, 1995, p. 239).

Os adultos de hoje já começam a se preocupar com a chegada da idade, procurando conhecer os impactos disso em si mesmos. Assim, é importante saber conduzir a forma de viver antes mesmo dos primeiros sinais de senilidade, como perda de visão e cabelos grisalhos. Existem vantagens e desvantagens no envelhecimento, o que requer estar atento a possíveis readaptações, não só fisiológicas, mas também sociais, por isso é preciso observar as disposições físicas e cognitivas e procurar ressignificar a vida, ocupando o cérebro com diversas atividades que lhes proporcione, senão prazer, ao menos, gosto pela vida.

A Europa e os Estados Unidos começaram a levantar questões sobre o conhecimento das transformações da expectativa de vida no Pós-Guerra. Debert (2004) apontou essa mudança como um problema social, uma vez que as pessoas da terceira idade reafirmavam novos modelos de vida na sociedade. Esse novo modelo de comportamento foi possível porque as pessoas dessa fase mantiveram a cognição e o exercício de sua autonomia para transitar nos espaços sociais, buscando novos aprendizados. No Brasil, segundo Debert (2004), o Serviço Social do Comércio (SESC) e a Legião Brasileira de Assistência (LBA) lançaram programas sociais voltados para as pessoas "idosas", promovendo atividades de lazer. Tais ações causaram um despertar nesse público para o conhecer, para o desafio de passar por novas experiências, por novos aprendizados.

A terceira idade, hoje, em sua maioria, busca ações voltadas para a área da educação, para novas formas de viver, reconstruindo uma nova rede de relações sociais (COSTA LIMA, 2014). A pessoa de mais idade, como vimos, é aquela que estava à procura de uma melhor qualidade de vida, valorizando o exercício da cidadania e o seu potencial produtivo, mesmo em uma nova faixa etária, buscando seu prazer e bem-estar individual, e, assim, melhorando a autoestima.

Pereira (2014) destaca a preocupação com a inserção social dos envelhescentes e das pessoas da terceira idade, considerando os interesses específicos desse universo heterogêneo por lazer, por ocupação do tempo livre e, acima de tudo, por qualidade de vida. Haddad (1997) evidencia que envelhescentes e pessoas da terceira idade se sentem mais saudáveis, de bem com a vida e de bom humor, quando se sentem ativos.

Se, no passado, envelhescentes e pessoas da terceira idade viviam em casa com tarefas domésticas para contribuir com a família, sem interesse de viver socialmente em instituições de educação, em restaurantes, em cinemas ou viajando, atualmente, esse grupo de pessoas diminuiu suas atividades domésticas e se 
motivaram para ir a locais públicos, para dar continuidade à vida pública, para (res)significar sua vida por meio de ações socioeducacionais e outras atividades, como viagens, aulas de pintura, exercícios físicos, etc.

Os envelhescentes e pessoas da terceira idade precisam dar continuidade às suas atividades físicas (da mente e do corpo). Ao longo dos anos, desde a infância até a idade adulta, eles estiveram descobrindo e estudando para atuarem profissionalmente a fim de obterem seu sustento. Ao saírem do mercado de trabalho, precisam refletir sobre a importância da continuidade de suas atividades, tanto do corpo como da mente, mas, ao mesmo tempo, precisam aprender a desacelerar o ritmo vivido durante toda a vida.

A terceira idade busca uma ressignificação em sua vida que conjugue prazer e ação, lazer e cidadania. Costa Lima (2014) identifica diferenças de comportamento entre os "produtivos" (pessoas da terceira idade aposentadas e reintegradas à sociedade) e os "improdutivos" (os que não mais desejam atuar no mercado de trabalho). E recomenda que, ao sair do mercado de trabalho, aposentando-se, os produtivos devem optar por não parar instantaneamente. $\mathrm{O}$ processo de deixar de ser produtivo deve acontecer de forma progressiva.

Hoje em dia, envelhescentes e pessoas da terceira idade têm consciência e controle sobre as suas ações sociais, experiências de vida e assumem um novo comportamento, desejando manter a sua função de ser guardião da memória social (COSTA LIMA, 2014).

\subsubsection{Envelhescentes e pessoas da terceira idade em busca de conhecimento}

Um dos fatores de crescimento pessoal é o conhecimento, que pode ser adquirido pelo acesso à educação, por experiências, por novas descobertas. Isso é possível graças ao processo de aprendizagem que acontece de forma contínua e por toda a vida. Sendo assim, é preciso desmistificar a crença de que os envelhescentes e pessoas da terceira idade são incapazes de aprender. Haddad (2000) chama a atenção para o fato de que, para a sociedade, pessoas nessa fase da vida são consideradas seres inúteis, não produtivas e que não possuem mais capacidade para buscar novos conhecimentos e oportunidades. Entretanto, "à medida que o indivíduo envelhece, sua capacidade intelectual torna-se mais aguda e mais seletiva [...] o intelectual idoso não diminui sua atividade mental. O que diminui é sua capacidade física” (HADDAD, 1986, p. 28-29). Dessa forma,

a educação para a Terceira idade remete ao verdadeiro sentido e objetivo da educação, como finalidade do processo civilizatório, aumento do nível intelectual e cultural dos cidadãos, uma teoria e uma prática de ação transformadora. (PONTAROLO; OLIVEIRA, 2008, p. 119) 
Vemos a escola como a casa do saber, local seguro onde os pais deixam suas crianças a fim de que lhes sejam transmitidos novos conhecimentos. Assim como acontece com as crianças, envelhescentes e pessoas da terceira idade também necessitam evoluir, de forma a continuar tendo acesso a novos aprendizados (MENDES, 2012). No entanto, a educação e o aprender para os envelhescentes e pessoas da terceira idade têm sentido e objetivo diferentes do da infância e da adolescência. Procura-se a escola não apenas para a obtenção de um diploma, mas para estabelecer canais de comunicação com a sociedade: é também uma forma de sociabilização.

$\mathrm{Na}$ década de 1980, a Organização das Nações Unidas para a Educação, a Ciência e a Cultura (United Nations Educacional Science and Cultural Organization) - UNESCO, realizou estudos sobre a recondução da valorização para pessoas idosas e chegou às seguintes diretrizes:

1. Considerar menos o conteúdo e mais o despertar nela a capacidade de confiança em si mesma, de sua autonomia e o de desconstruir os estereótipos negativos que poderão estar influindo na sua vida. Aumentando o senso de suas responsabilidades, a pessoa idosa poderá melhorar sua saúde física e mental, o que contribuirá para que ela se afirme cada vez mais no dia-a-dia e no seu comportamento social;

2. Minimizar o isolamento, a solidão em que vivem muitos idosos, estimulando as relações com pessoas de sua geração e, também, com as de outras gerações; 3. Proporcionar conhecimentos práticos, específicos sobre, por exemplo, a passagem da vida ativa para a de aposentado, além de conhecimentos teóricos relativos ao processo de envelhecimento; ainda, atividades físicas, socioculturais e artísticas que possam interessar aos idosos;

4. Proporcionar a tomada de consciência das pessoas idosas da riqueza de sua vida pessoal e profissional e da importância da comunicação de sua experiência a outras gerações, desenvolvendo o equilíbrio e a compreensão mútua num mundo tão conflitado e que muda rapidamente. (SCHONS; PALMA, 2000, p. 162)

Essas diretrizes se referem a cursos e atividades educacionais desenvolvidas especificamente para o público formado por envelhescentes e pessoas da terceira idade. Para muitos envelhescentes e pessoas da terceira idade, a passagem pela escola pode não ter sido muito produtiva por várias razões: impossibilidade socioeconômica, restrição familiar, distância do local de moradia e falta de acesso, etc. Entretanto, para outros, a escola pode ser sinônimo de boas recordações: ascensão socioeconômica, estímulo e valorização familiar, oportunidade melhor de aprendizagem, etc. Por isso, programas educacionais específicos para a envelhescência e terceira idade que valorizam a sua qualidade de vida e identidade própria são importantes. 
Havendo oportunidade de uma participação ativa e de qualidade para envelhescentes e pessoas de terceira idade, o Brasil poderia oferecer uma nova experiência a esse público, dando-lhe a oportunidade de interação com os jovens, o que permitiria ganhos também a estes, que usufruiriam dos conhecimentos profissionais e de mundo que os envelhescentes e terceira idade podem compartilhar.

Atualmente, já há crescente busca de envelhescentes e pessoas da terceira idade por educação. Os que ainda estão no mercado de trabalho já começam a sentir a necessidade de obter aperfeiçoamento profissional (HADDAD, 1997). Dados do Censo da Educação Superior de 2014, compilados no Anuário Brasileiro de Educação Básica 2016 e 2017 (TODOS PELA EDUCAÇÃO, 2016, 2017), evidenciam mudança no interesse pelo acesso à educação superior, que antecipam já os efeitos do impacto da mudança sociodemográfica (Gráfico 2).
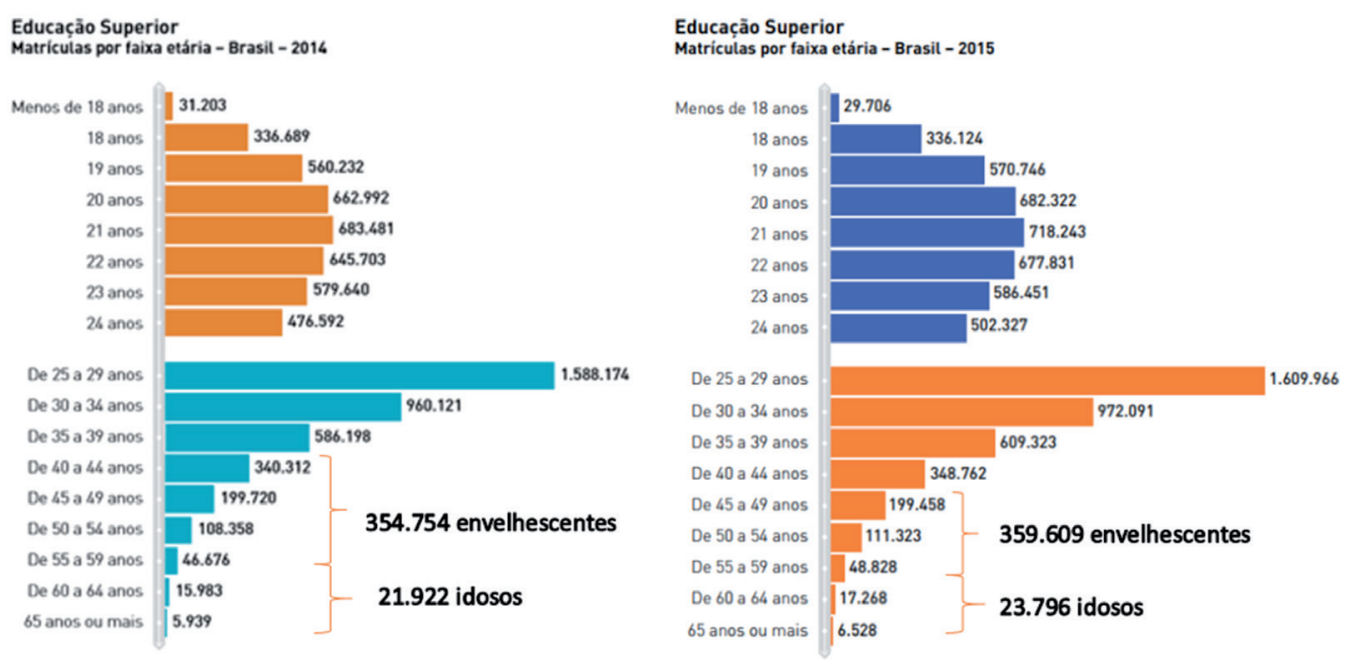

Gráfico 2 Distribuição das matrículas por faixa etária na educação superior nos anos de 2014 e 2015

Fonte: Elaborado a partir de dados do Censo da Educação Superior, INEP.

Nos últimos anos, a expansão das matrículas nas Instituições de Ensino Superior (IES) do país foi uma constante e prospecta-se que, até 2025, haja ainda $58 \%$ de crescimento. O Gráfico 2 evidencia a existência de mais de 700 mil pessoas com mais de 40 anos matriculadas na educação superior no Brasil. Esse número só tende a subir, já que a identidade demográfica do Brasil será modificada a partir de 2025, com a inversão da pirâmide etária.

Atualmente, os anseios e expectativas desse público são diferentes do público regular do ensino superior. Por exemplo, bolsas de programas institucionais de 
iniciação científica, extensão, docência, tecnológica, etc. geralmente são ocupadas por estudantes que não tenham vínculo empregatício ou renda; o público de mais de 40 anos, portanto, fica de fora dessas oportunidades de desenvolvimento. Num futuro próximo, a distribuição dessas bolsas deve ser repensada em atendimento às políticas de inclusão do público envelhescente e terceira idade.

\subsubsection{Políticas públicas para envelhescência e terceira idade}

No novo milênio, o mundo lançou um novo olhar sobre as reivindicações por políticas públicas socioeducacionais. De acordo com essa nova demanda, é necessário fomentar espaços que propiciem à população da terceira idade o conhecimento de sua realidade, além de promover a qualificação dos profissionais da área e definir práticas que sejam adequadas às características dos alunos idosos, isto é, é preciso estar respaldado no reconhecimento dos direitos humanos estabelecidos pela Organização das Nações Unidas (ONU) e nos princípios da independência, participação, dignidade, assistência e autorrealização que visam ao seu desenvolvimento integral e proporcionam igualdade de oportunidade a todos.

A inversão na pirâmide etária, com muito mais idosos do que crianças, nos trará muitos impactos sobre como ressignificar a vida de todos nós nas relações familiares, sociais, profissionais, saúde e educacional.

Segundo Neri e Freire (2000), a qualidade de vida na velhice é o resultado da interação do homem com a sua história, ou seja, é o fruto da interação entre indivíduos, normas e valores sociais que sofrem alteração no decorrer do tempo.

Lawton (1991) propôs quatro aspectos que devem ser avaliados na qualidade de vida: 1) bem-estar psicológico; 2) percepção de qualidade de vida; 3) competências comportamentais e 4) objetivo do entorno físico.

Tal cenário obriga o Estado a dar uma maior proteção a crianças, envelhescentes e pessoas da terceira idade, ante sua fragilidade e necessidade de apoio em relação à saúde, à educação, a acesso à justiça, etc. É preciso também dar maior proteção previdenciária ao público da terceira idade para que sejam garantidos os seus direitos pelos serviços prestados.

No Brasil, a partir da Carta Magna de 1988, cria-se a Lei n. 8.842/1994, conhecida como Política Nacional do Idoso, a qual sofreu várias alterações nos últimos anos. Problemas com a execução dessa lei resultaram na elaboração da Lei n. 10.741, conhecida como Estatuto do Idoso, sancionada em $1^{\circ}$ de outubro de 2003 pelo Presidente Luiz Inácio Lula da Silva. Essa lei, em seu artigo $1^{\circ}$, tem como objetivo "regular os direitos assegurados às pessoas com idade igual ou superior a 60 (sessenta) anos de idade" (BRASIL, 2003). 
Ainda assim, a Presidente Dilma Rousseff promulgou um decreto-lei sobre o Estatuto do Idoso, em $1^{\circ}$ de outubro de 2013, dia nacional do idoso, para estabelecer que se faça cumprir a lei em vigor há 10 anos, bem como dar encaminhamentos para o Estado se responsabilizar por uma melhor assistência ao idoso, auxiliar nas construções de casas adaptadas e assegurar o direito legal de estudo nas Universidades Abertas.

No Título I, nas disposições preliminares dos três primeiros artigos da legislação atual, define-se "idoso" a partir de 60 anos de idade, ao qual se deve oferecer todas as oportunidades e facilidades, para preservação de sua saúde física e mental e seu aperfeiçoamento intelectual, espiritual e social, em condições de liberdade e dignidade. $\mathrm{Na}$ sequência dos artigos, são definidas as obrigações da família e da comunidade, da sociedade e do Poder Público e a efetivação do direito à vida, à saúde e à alimentação dos idosos, o que pode ser sumarizado do seguinte modo:

- A população em geral ainda não tem consciência plena dos itens da lei, de sua aplicabilidade e de sua prioridade.

- A lei chama a atenção para novas formulações e execuções de políticas públicas sociais específicas.

- A lei prevê a garantia de proteção ao idoso.

- É objeto da lei prever a ocupação e o convívio com o idoso das demais gerações.

- A lei destaca a priorização do atendimento ao idoso por sua própria família.

- Faz-se necessário investir em capacitação e reciclagem dos recursos humanos nas áreas de geriatria e gerontologia e na prestação de serviços aos idosos.

- O favorecimento de divulgação de informações de caráter educativo sobre os aspectos biopsicossociais de envelhecimento.

- A lei prevê garantia de acesso à rede de serviços de saúde e de assistência social local e prioridade no recebimento da restituição do Imposto de Renda (incluído pela Lei n. 11.765/2008).

Tendo em vista a melhoria da qualidade de vida, o artigo 20 do Estatuto do Idoso prevê a inserção desse grupo populacional em atividades educativas: "o idoso, nos termos da lei, tem direito à educação, cultura, esporte, lazer, diversões, espetáculos, produtos e serviços que respeitem sua peculiar condição de idade" (BRASIL, 2003).

Embora a lei vigente proteja e dê o direito de acesso a universidades, com a garantia de que "o Poder Público criará oportunidades de acesso do idoso à edu- 
cação, adequando currículos, metodologias e material didático aos programas educacionais a ele destinados" (art. 21 do Estatuto do Idoso), envelhescentes e pessoas de terceira idade passam por muitas dificuldades para ter acesso a esse direito, que muitas vezes os fazem desistir. Necessitam fazer um cadastro para pleitear vaga nos projetos ou cursos de extensão e solicitar o que lhes interessam. Entretanto, essas escolhas são limitadas ante a pouca oferta de cursos destinados a esse público.

Para Costa Lima (2014) e Pereira (2014), as universidades precisam investir na formação de profissionais, particularmente nos campos da educação e saúde, aptos a trabalhar com as especialidades desse contingente populacional. Trata-se de uma oportunidade de os professores desenvolverem projetos nas universidades direcionados à formação de futuros professores que se qualifiquem para atuar na educação de envelhescentes e pessoas da terceira idade.

Knowles, Holton III e Swanson (1998) enfatizam que:

a andragogia é uma ciência que procura desenvolver uma teoria específica para a aprendizagem relacionada a pessoas adultas. Conforme o autor, na Andragogia, assim como na teoria Humanista, acredita-se que a aprendizagem significativa leva a insights que fazem com que as pessoas entendam a si mesmas e aos outros. (KNOWLES; HOLTON III; SWANSON, 1998, p. 4)

Assim, é preciso que os docentes estejam preparados para lidar com esse público. O número de ingressantes envelhescentes e da terceira idade no ensino superior é crescente. Ante essa nova demanda, é importante que haja mudanças na matriz curricular dos cursos de formação de professores de todas as IES para se adequarem às necessidades específicas ligadas àquele público.

No cenário atual, faz-se necessário que a educação superior ofereça uma melhor e mais ampla formação intelectual e profissional, valorizando esse público de forma crítica e consciente sobre sua participação e inserção na sociedade. No entanto, apesar de a legislação prever, como vimos no artigo 22 do Estatuto do Idoso, a abordagem do tema não é institucionalizada nos componentes curriculares dos cursos, pelo menos no curso de Licenciatura Letras-Inglês da Universidade Federal de Sergipe. Esse tema, se abordado, é por iniciativa de algum docente que deseja inserir essa discussão em suas aulas e ou em projetos de extensão.

Diante da realidade do aumento da expectativa de vida da população brasileira comprovado por dados estatísticos, diante do acesso mais frequente de envelhescentes e pessoas da terceira idade às universidades e diante da legislação vigente, que assegura o direito a educação com metodologias que se adequem a suas 
especificidades, faz-se mister que professores e alunos das universidades comecem a despertar para novos aprendizados profissionais e possam, assim, se preparar de forma específica para atender a esse público, de modo que a aprendizagem de uma língua estrangeira seja apenas uma das possibilidades de inserção social, que lhes permita novos sentidos e ressignificação da vida.

\subsubsection{Aprender uma nova língua na envelhescência e na terceira idade}

Numa sociedade com tamanha variedade de culturas e línguas, tendo à sua disposição as facilidades de comunicação por meio de novas tecnologias, intensifica-se a busca por diversificados tipos de conhecimentos, inclusive a aprendizagem de novas línguas.

A participação de envelhescentes e pessoas da terceira idade em curso de uma língua estrangeira, além de promover novos conhecimentos de uma nova língua, proporciona novas relações sociais entre sujeitos de várias idades (PIZZOLATTO, 2008). Dessa forma, tanto os aprendizes quanto os ministrantes devem saber lidar com a realidade do ensinar e do aprender a língua.

No cenário atual, envelhescentes e pessoas da terceira idade acompanham o ritmo acelerado da modernidade, não só navegando pela internet para obter novas experiências de aprendizagem, protegendo-se de possíveis doenças e de perdas cognitivas ao utilizar o conhecimento adquirido, mas também almejando aprender uma nova língua para, nessa nova fase da vida, adquirir conhecimentos sobre a cultura do país que gostariam de visitar.

Embora envelhescentes e pessoas da terceira idade estejam conscientes dos seus direitos sob a legislação atual, faz-se necessário entender essas mudanças para ajudar a romper com o estereótipo de que as pessoas em processo de envelhecimento não têm mais idade para aprender. $\mathrm{Na}$ contramão desse estereótipo, os envelhescentes se motivam cada vez mais para aprender uma língua estrangeira, desmistificando alguns preconceitos sobre a impossibilidade de aprendizagem na envelhescência e na terceira idade.

Como em 2025 a maior parte da população será de envelhescentes e de pessoas da terceira idade, o mercado de trabalho necessita formar mão de obra especializada para o ensino de inglês em todas as unidades educacionais. É preciso pensar em políticas públicas que se adequem às demandas necessárias a esse público específico, podendo proporcionar a todos eles uma melhor qualidade de vida ao darem continuidade aos estudos; no nosso caso, proporcionar o aprendizado de uma língua estrangeira - o inglês - contribuindo, assim, para reativar o circuito neuronal, evitando possíveis doenças degenerativas e fazendo com que eles mantenham sua cognição. 
Como veremos a seguir, envelhescentes e pessoas da terceira idade têm consciência de modificar o comportamento pessoal por meio do exercício da percepção, da atenção, da concentração, respeitando-se, é claro, o ritmo de aprendizagem de cada um. Por vezes, eles necessitam repetir reiteradamente, por exemplo, a pronúncia de determinadas palavras ao estarem aprendendo uma língua estrangeira. Quando a repetição não é suficiente para a aprendizagem, cabe ao profissional que atua com esse público criar estratégias que façam com que o objetivo seja atingido. Para isso ele precisa ter uma formação diferenciada, na medida em que, nesse processo de aprendizagem, estão envolvidos aspectos cognitivos e neuronais diferentes.

\subsection{TEMPO COGNITIVO}

O conceito de cognição é utilizado para nos referirmos às atividades mentais como ver, entender, lembrar e resolver problemas. Está relacionado aos processamentos das informações transmitidas que operam em duplo sentido, que vai do emissor ao receptor e vice-versa. Esse conceito se insere em estudos voltados para as áreas do circuito neuronal e da psiquiatria ligada à neurociência. Dehaene (2012) afirma que a cognição abrange as ações mentais e, por esse motivo, não é possível saber de tudo, por essas ações mentais serem privativas dos pensamentos secretos. Não são observáveis a olho nu, mas podem ser estudadas cientificamente com base em evidências indiretas, através do comportamento individual do ser, das expressões da fala e de hipóteses.

Além das teorias comportamentais, as novas teorias foram estudadas através da percepção, da atenção, da memória, da fala, de solução de problemas, da informação selecionada, codificada e armazenada, dando maior importância ao processamento de interação e entorno com o outro. A psicologia cognitiva estuda os processos cognitivos de percepção, atenção, retenção temporária e permanente, a compreensão da fala, a retenção e produção da aprendizagem conceitual e de raciocínio, bem como a resolução de problemas e o raciocínio dedutivo. A aprendizagem acontece quando habilidades são automatizadas.

As áreas da neurologia, da psiquiatria, da filosofia, da antropologia e computacional são alguns exemplos de áreas científicas que interagem com estudos sobre a manutenção do bem-estar cognitivo do ser humano. Elas contribuem para que se evitem demências em decorrência do processo natural do envelhecimento.

A dimensão do tempo cognitivo que influencia o aprendizado de uma língua está relacionada fisiologicamente com os processos da linguagem, como podemos ver a seguir. 


\subsubsection{Tempo de execução de tarefas e envelhecimento}

Ainda que a idade de 60 anos seja o início do envelhecimento, oficialmente decretado pela lei vigente nacional, não podemos afirmar que uma pessoa nessa idade esteja idosa. O fato é que toda pessoa no processo de envelhecimento passa por modificações no desempenho cognitivo. Os sinais dessas modificações vão aparecendo aos poucos ou mais acentuadamente a depender da pessoa. Na maioria dos casos, quando não se trata de doença degenerativa, é um processo natural de uma nova fase de início da senilidade.

Para entender a cognição humana, é preciso desvendar os segredos do cérebro. No século XIX, Vigotski (2000) fazia experiências com animais e percebia que eles davam respostas positivas depois de serem estimulados. Essas experiências fizeram com que os estudos sobre o cérebro humano avançassem, aplicando a mesma técnica de estímulo-resposta. O avanço da ciência tem contribuído com a correção de imperfeições da natureza e promovido melhor qualidade de vida ao ser humano.

Atualmente é possível a identificação das áreas cerebrais onde existem patologias físicas, cognitivas ou sensoriais, como AVC, meningite, doenças degenerativas, esclerose múltipla e doenças dos cérebros. Áreas do conhecimento como neurologia, fisioterapia e fonoaudiologia têm atuado na pesquisa de patologias e demências ligadas à senilidade. Estudos neurolinguísticos têm evidenciado a relação entre neurônios, linguagem e envelhecimento.

O cérebro é um órgão que faz parte do sistema nervoso que comanda as emoções do consciente e do inconsciente. Izquierdo (2004), Gabriel (2004), Dehaene (2012), Lent (2005), Bialystok, Craik e Ruocco (2006) têm se dedicado a estudar a prevenção de demências cerebrais e a atuação do cérebro e da mente a fim de compreender como os neurônios funcionam no processo de aprendizagem de uma língua estrangeira.

Segundo Lent (2005), o neurônio é a unidade básica do processamento da informação. Ele é considerado a unidade morfofuncional situado no sistema nervoso que produz e veicula diminutos sinais elétricos, que são verdadeiros bits de informações, capazes de codificar tudo que sentimos, a partir do ambiente externo e interno, e tudo que pensamos. Seu tamanho é variável, mas, em média, mede um micrometro.

Ainda segundo Lent (2005), os neurônios operam em conjunto, emergindo aptidões mentais e cognitivas, memórias, inteligências e emoções. Embora não exista um controle de seu desenvolvimento individual, os estudos confirmam que as células nervosas crescem e podem ser modificadas a depender de respostas a experiências positivas e ou negativas. 
O neurônio faz várias conexões ao mesmo tempo. Cada conexão chama-se sinapse. Possuímos a capacidade de receber muitas informações ao mesmo tempo, inclusive sobre as percepções da emoção. De acordo com Dehaene (2012), no processamento da leitura, por exemplo, os estímulos visuais ativam milhões de neurônios simultaneamente das regiões cerebrais encarregadas por essa tarefa.

Apesar de haver uma pré-disposição genética que diferencie a capacidade cognitiva de cada ser humano, isso não é obstáculo à aprendizagem: experiências e estímulos podem suprir a carência genética.

Izquierdo (2011) conceitua a memória como a aquisição de informações provenientes de dentro dos sujeitos. Contudo, a capacidade de manter essa memória ativa varia de acordo com a idade: o jovem adquire e conserva a memória com muito mais facilidade do que as pessoas que atingem a terceira idade. A memória dessas pessoas registra os fatos do passado, de quando eram jovens, mas os registros atuais já não são marcados com tanta facilidade.

A memória é um elemento essencial para que haja aprendizagem. Existem vários tipos de memória: memória curta, memória de longo prazo, memória associativa. Isso está relacionado à plasticidade sináptica. O processo de recuperação das informações se dá através da ativação de neurônios específicos, o que pode ativar as memórias armazenadas durante a passagem pelas várias faixas etárias. Quando a pessoa atinge a idade adulta e, posteriormente, a terceira idade, é natural que aconteça algum tipo de diminuição da plasticidade neural ou sináptica por questões biológicas, acarretando dificuldade de lembrar. Entretanto, para se ter qualidade de vida, é preciso continuar obtendo a independência do saber selecionar, organizar e executar as ações interligadas ao comando cerebral.

Assim, mesmo que o sujeito esteja com a capacidade cognitiva normal, faz-se necessário que mantenha as atividades do cotidiano, a fim de que não surjam problemas de doenças neurológicas futuros. Observe-se também que o ritmo do ‘tempo' de execução das tarefas pode aumentar drasticamente quando a pessoa está enferma ou em idade mais avançada.

As demências neurodegenerativas podem acelerar o processo de envelhecimento, mas se envelhescente e pessoa da terceira idade se conscientizarem e trabalharem as funções cognitivas, é possível um retardamento do processo degenerativo e sua qualidade de vida será melhor.

No processo normal de envelhecimento, as famílias não estão atentas aos comportamentos dos envelhescentes e das pessoas de terceira idade, o que, por vezes, não permite detectar algumas possíveis demências nesses familiares. $\mathrm{O}$ envelhecimento fisiológico está associado a um declínio gradual nas funções cognitivas. Dificuldade para recordar nomes de pessoas, números de telefone e objetos guardados são as manifestações mais comuns. Esse declínio da cognição, que 
acompanha o envelhecimento, tem início e progressão variáveis, dependendo de instrução, nível intelectual, saúde, personalidade e da capacidade mental individual (REIS et al., 2009).

O diagnóstico cognitivo comportamental é muito complexo devido à variedade de grupos de pessoas da terceira idade que possuem histórico hereditário. Além disso, a falta de conhecimento sobre essas enfermidades e a falta de observação do idoso por parte dos familiares dificultam ou retardam a procura por um diagnóstico e possível tratamento. Segundo Engelhardt et al. (1998), existem quadros leves de pacientes com comprometimento cognitivo que são frequentes, passando muitas vezes despercebidos, e há uma necessidade de distinguir entre as manifestações iniciais de doença e modificações associadas ao processo normal de envelhecimento.

Pesquisas têm revelado que o grau de escolarização interfere no processo de envelhecimento do cérebro, atuando como um fator de proteção neuronal. $\mathrm{O}$ desempenho de indivíduos testados com instrumentos de avaliação cognitiva é fortemente influenciado pela escolaridade. Reis et al. (2009) desenvolveram testes de aptidão cognitiva cujos resultados da aplicação entre idosos de 65 a 80 anos de idade evidenciam melhor desempenho entre aqueles que estudaram em detrimento daqueles que não estudaram.

Nas funções cognitivas, $40 \%$ dos sujeitos apresentavam estado preservado e $60 \%$ dos demais idosos apresentavam alguma alteração cognitiva entre 60 e 80 anos de idade. Não é só a idade que influencia no processo de alteração cognitiva, a escolarização também: quando se estimulam os hemisférios do cérebro, a tendência é de se preservar mais pelas ações neuronais, para uma melhor qualidade de vida. No entanto, Reis et al. (2009) enfatizam o quão difícil é falar cientificamente sobre os desempenhos cognitivos entre participantes escolarizados e não escolarizados devido ao fator motivação individual que cada participante possui.

Embora as alterações cognitivas possam levar ao surgimento de demências, existe muita dificuldade de se diagnosticar o grau de declínio não patológico do patológico (COELHO et al., 2012). Mas, mesmo diante dessa dificuldade, resultados de estudos evidenciam que pessoas da terceira idade que não tiveram acesso à escolarização apresentam menor desempenho em alguns dos testes cognitivos.

Os estudos de Xavier e Parente (2006) e Ávila et al. (2009) evidenciam que houve influência significativa na velocidade de processamento, atenção, funções executivas, memória e inteligência sobre as tomadas de decisões em dois grupos de participantes: idosos com escolarização e sem escolarização. Os autores ratificam a importância da continuidade de estudos das pessoas no processo de envelhecimento, a fim de praticar ações que envolvam o raciocínio do circuito neuronal para tornar o cérebro mais resistente a possíveis declínios. 
Na mesma direção, Coelho et al. (2012) mostram que pessoas envelhescentes e da terceira idade que praticam atividades físicas sistematizadas e regulares melhoram substancialmente as funções cognitivas e também o desempenho cognitivo, diferentemente do grupo de pessoas do mesmo público que não praticava atividades físicas. Nesse estudo, Coelho et al. (2012) visavam a avaliar o desempenho cognitivo de memória de curto prazo, linguagem, aprendizagem, o grau de esquecimento e funções executivas em diferentes níveis escolares de adultos e idosos praticantes de atividades físicas por um tempo superior a seis meses. $\mathrm{O}$ projeto AFRID (Atividade Física Recreativa para a Terceira Idade, da Universidade Federal de Uberlândia) envolveu 132 participantes com a idade a partir de 45 anos e 60 anos com o objetivo de manter a qualidade de vida. Dos 132 participantes, dez apresentaram Mini Exame do Estado Mental (MEEM), com resultados abaixo da média de escolaridade. E, diante desse resultado, ficaram apenas 122 indivíduos sem perdas cognitivas entre as idades de 46 a 85 anos. Foi utilizado o teste WMS-R, para avaliar a aprendizagem e a taxa de esquecimento, entre palavras sequenciais, e o Mini Exame do Estado Mental (MEEM), composto por questões agrupadas, orientação sobre o tempo, local, registro de três palavras, linguagem e capacidade visual construtiva; o score desse teste varia de 0 a 30 pontos, e, quanto mais baixo for o valor, pior está o desempenho cognitivo (COELHO et al., 2012).

Além desses testes, foram aplicados o teste do desenho do relógio (TDR), um relógio com inversão de letras e o teste de fluência verbal semântica (TFV), que é um instrumento simples que avalia o desempenho em relação às respostas em um número maior possível da mesma categoria semântica em um minuto. Os resultados do estudo de Coelho et al. (2012) apontaram que o desempenho dos idosos praticantes de atividades física é similar para os diferentes níveis de escolaridade, mas que os estudos são inconclusivos, necessitando efetuar, em novas pesquisas, se a atividade física exerce efeito protetor nas funções cognitivas independentemente do nível de instrução do indivíduo.

Observemos a seguir as decisões que envelhescentes e pessoas da terceira idade tomam em ações de uma atividade lúdica, conforme o estudo de Santos, Rosseti e Ortega (2006), segundo o qual o funcionamento de tomada de consciência de idosos e adolescentes no contexto de jogos de regras favorece a relação social entre jovens. Em uma abordagem exploratória de natureza qualitativa, com dois adolescentes e dois idosos jovens, em um jogo de regras chamado Quoridor, os participantes utilizaram estratégias para vencer o jogo. Foi realizado experimento para checar a cognição entre as tomadas de decisões dos grupos de participantes jovens e idosos e o resultado evidenciou que, embora os idosos sejam mais lentos nas ações, eles conversavam mais entre si para chegar no alcance final de vencer o jogo, enquanto os participantes jovens também, mas com menos 
estratégias. Esse resultado denota que a habilidade da experiência de vida favoreceu o sucesso de ter vencido o jogo, embora tenha maior demanda de tempo na tomada de decisão.

Obler e Pekkala (2008) investigaram problemas de linguagem e a comunicação no envelhecimento. As pessoas idosas se queixam de problemas auditivos em situações de locais barulhentos como também de ter dificuldades em identificar certos tipos de palavras. Também sabemos, em relação à língua, que, com o passar da idade, há mudanças na saúde dos idosos em relação à verbalização (processo cognitivo): “A compreensão da recuperação dos aspectos lexicais para narrar e soletrar podem acontecer. Em outras áreas da linguagem, mostram pouco ou nenhum declínio em relação ao avanço da idade" (OBLER; PEKKALA, 2008, p. 351). ${ }^{2}$ Isso significa que, mesmo tendo-se alguma perda de cognição, as pessoas podem demonstrar poucas áreas afetadas e manter outras regiões da área da linguagem ativas.

Do mesmo modo, os estímulos podem devolver a pessoas de terceira idade a manutenção de cognição e motivação em exercitar as línguas. As funções fisiológicas vão variar de acordo com o estilo de vida dos sujeitos da terceira idade.

Obler e Pekkala (2008) destacam que pode haver problemas com respeito à recuperação de identificar a palavra específica, por exemplo, em tarefas de identificação de palavras ou tarefas que sejam para confrontar nomes, tarefas sobre a definição e fazer inversão de conceitos para serem identificadas as palavras. Os autores reportam o estudo de Bowles, Grimm, McArdle (2005), que constataram que, em relação ao uso de vocabulário, há um declínio significativo com o avanço da idade do que o próprio avanço do vocabulário entre indivíduos de 35-70 anos, assim como o pico da idade aguçada é de 50 anos e posteriormente inicia o declínio.

Por que os adultos mais velhos têm problemas com lembranças de nomes e coisas? Burke e Shafto (2004) conduziram uma série de estudos para responder a

2 "Comprehension problem can also be observed, specially for auditory material that consists of complex text or is produced in stressful (such as noisy) conditions. Discourse patterns may change as well, depending on the nature of the tasks eliciting them. For elders who are bilinguals, these problems may be accompanied by attrition or less-used language. More severe lexical-retrieval and comprehension problems are seen in elderly individuals who display mild cognitive impairment (MCI) or progress to Alzheimer's disease (AD) and all aspects of language and communication are impaired in the late stage of Alzheimer's dementia. Age-related language changes have been explained as language-specific or related to cognitive abilities such as memory and attention, and have been attributed to areas of the brain that undergo substantial age-related changes." 
essa questão. O modelo aplicado foi "a hipótese de déficit de transmissão", segundo o qual as palavras são elencadas em uma via semântica, fonológica e ortográfica para que, juntas, facilitem a compreensão do conhecimento da palavra com a ativação cognitiva, que sofrem efeito de falta da atenção e memória, processos mentais que podem declinar com avanço da idade. Os resultados apontam que participantes mais velhos tendem a experienciar mais palavras problemáticas do que os mais jovens. Eles experienciaram esses testes como em outra língua, ou eles omitem elementos por lapsos da língua. A expressão "na ponta da língua" ocorre quando as marcas da língua fonológica do item lexical não atingem a saída suficientemente; o falante conhece a palavra, mas é incapaz de pronunciá-la no exato momento.

No início do envelhecimento, os problemas de compreensão estão relacionados a vários fatores cognitivos, que podem ser diagnosticados de acordo com a situação dos sujeitos, tais como o problema sobre a rapidez ou lentidão da compreensão do texto em áudio (WINGFIELD; PEELLE; GROSSMAN, 2003); a dificuldade em reconhecer sotaques, variantes fonológicos que determinam a região do falante, e, por isso, nem sempre o sujeito envelhescente terá a habilidade em detectar a origem do falante (BERGMAN, 1980). Burke e Shafto (2004) evidenciam que os problemas de compreensão podem estar voltados para as estruturas complexas de sintaxe e que as pessoas da terceira idade necessitam usar inferência para poder compreender o texto.

Reis et al. (2009) relataram a carência de estudos na terceira idade e que o estudo de uma língua estrangeira seria como um efeito terapêutico, preventivo de doenças do cérebro. Por isso é de grande importância uma pesquisa que venha contribuir com futuros resultados de prevenção dessas demências causadas talvez pela falta do exercício de uso do cérebro. Na realidade de países em desenvolvimento, como o Brasil, o grande número de pessoas com pouco ou nenhum grau de escolaridade releva a necessidade da existência de políticas públicas voltadas à prevenção e ao tratamento dessas possíveis doenças de grau leve ou de grau patológico, cuja incidência aumenta rapidamente diante da faixa etária de 80 a 90 anos. Uma estratégia para o controle desse aceleramento na perda de cognição é o estudo de uma língua estrangeira, por estar ativando os dois lados do hemisfério (esquerdo e direito), como veremos a seguir.

\subsubsection{Linguagem, cognição e envelhecimento}

Existem muitas teorias para a aquisição da linguagem. Todas elas têm em comum o fato de que é da natureza humana nascer com a possibilidade de poder falar e que o desenvolvimento da fala envolve a maturação fisiológica. Em seu 
desenvolvimento fisiológico, ao adquirir os primeiros comportamentos da fala, a área frontal do cérebro de uma criança é a última a se formar no seu desenvolvimento normal (entre 0-4-5 anos de idade) e é a primeira a ser degenerada na terceira idade quando acometido de demências (LENT, 2005).

Muitos estudos evidenciam que aprender uma língua estrangeira é um exercício que pode reativar o circuito neuronal entre os hemisférios do cérebro (LENT, 2005, BIALYSTOK; CRAIK; RUOCCO, 2006). Essa compreensão é atribuída à área frontal do cérebro, que é a base da atenção e da realização das tarefas simultâneas. Bialystok, Craik e Ruocco (2006) evidenciam que, ativando os dois hemisférios do cérebro, o ensino de uma língua estrangeira faz com que pessoas da terceira idade exercitem o cérebro e gerenciem a sua atenção o tempo inteiro, muito mais que os monolíngues, tornando-os mais eficientes e mais fortes. Bialystok, Craik e Ruocco (2008) defendem que, do ponto de vista fisiológico e cognitivo, ser bilíngue só traz vantagem. Segundo Obler e Pekkala (2006), os bilíngues usam o lobo frontal, aprimorando o cérebro como compensação do declínio da função medial; em termos de uso, isso significa que

Pessoas que dominam mais de uma língua, têm mais vantagens do que aqueles que falam apenas a sua língua. [...] outros estudos indicam que as pessoas idosas bilíngues, que têm uma longa experiência em usar duas línguas têm desenvolvido melhores funções da área da memória executiva nos quais podem ser mais eficazes no uso do processamento da língua do que os adultos mais velhos monolíngues. [...] com o objetivo de superar dificuldades dos nomes da memória, ambos falantes monolíngues ou bilíngues podem usar estratégias diferentes, assim como evitar o uso das expressões e signos linguísticos. Os idosos bilíngues podem também se apropriar de palavras de outras línguas ou intercalar de uma língua para outra, se o interlocutor falar ambas as línguas. (OBLER; PEKKALA, 2008, p. 353) (tradução nossa) ${ }^{3}$

Tendo em vista essas constatações, envelhescentes e pessoas da terceira idade precisam ser estimulados a desenvolver a área frontal do cérebro. Aprender uma

3 "People who master more than one language have advantages over those who master only one. [...] Other studies indicate that those elderly bilinguals who have lifelong experience in using two different languages have developed better executive function and working memory, which they can more effectively use for processing language than monolingual older adults. [...] In order to overcome such naming difficulties, both monolingual and bilingual adult speakers may use different strategies such as avoidance, rephrasing, and circumlocutions. Bilingual elders, as well can borrow words from the other language or code-switch from one language to the other, if the interlocutor speaks both languages.” (OBLER; PEKKALA, 2008) 
língua estrangeira é um incentivo ao exercício entre as conexões neuronais. Tendo as sinapses reativadas, o aprendiz da terceira idade se motiva e se interessa para desenvolver outras tarefas de aprendizagem (BIALYSTOK; CRAIK; RUOCCO, 2006). Esse exercício das conexões neuronais favorece as pessoas envelhescentes e da terceira idade a manterem os dois hemisférios cerebrais simultaneamente em relação ao vocabulário de ambas as línguas, além de outros processos de prevenção contra demência, chamando a atenção para as ações individuais de aprendizagem.

Lent (2005) subdivide as ações de tarefas a serem executadas pelo cérebro em funções específicas e funções globais. As primeiras estão ligadas ao hemisfério esquerdo do cérebro, onde estariam as atividades dos cálculos dos números, fala, escrita, identificação de pessoas, parte motora lateral, identificação de objetos e animais, compreensão linguística, leitura e relações espaciais qualitativas e, sendo assim, as articulações da fala sobre a organização sistêmica de cada língua, letras, palavras, frases e verbalização, saber fazer a seleção de números, diferenciar as pessoas entre si, a parte motora e a compreensão linguística no espaço global em que se vive.

Segundo Lent (2005), o conceito de especialização superou o conceito antigo de dominância pelo qual um dos hemisférios do cérebro faria tudo, sendo o outro 'uma reserva técnica coadjuvante'. As funções globais do cérebro estão ligadas diretamente ao hemisfério direito. As tarefas são identificadas como: identificação de pessoas, objetos, compreensão musical, bem como as relações espaciais qualitativas. No entanto, questões sobre linguagem articulatória estão voltadas para o hemisfério esquerdo e o hemisfério direito é voltado para conotação, ironia, aspectos discursivos e pragmáticos. Scherer e Gabriel (2007) subdividem o uso das tarefas dos hemisférios cerebrais em core coding e fine coding como um entrelaçamento das tarefas globais e específicas em que estejam sendo utilizadas no momento das ações de suas tarefas.

Lent (2005) enfatiza as funções globais do hemisfério esquerdo do cérebro, praticamente o responsável por tantas identificações, por outro lado, o hemisfério direito seria o corresponsável pelas emoções e compreensão da linguagem. Assim, não se pode afirmar com precisão se existem essas divisões de tarefas sobre articulação da fala e sua compreensão, por exemplo. Portanto, os hemisférios cerebrais se entrelaçam fazendo individualmente as suas seleções; quando é necessário o core coding, o hemisfério direito é o responsável pelas possíveis significações da palavra, e o hemisfério esquerdo para selecionar dentre as opções disponibilizadas, a mais adequada para o contexto a ser inserido, o chamado fine coding (SCHERER; GABRIEL, 2007). 
Entendemos essas tarefas das acepções do conhecimento sistêmico a serem executadas nos dois hemisférios cerebrais como as mais coerentes para identificação do uso da palavra adequada pelo cérebro e fazer a opção de escolha de acordo com a seu grau de conhecimento da língua e visão sobre o assunto.

Neurônios podem ser estimulados ou enfraquecidos de acordo com os padrões de ativação das áreas neuronais. Por isso, quando as pessoas envelhecem e se isolam passam a perder muitas das acepções cognitivas e metacognitivas, a começar pela carência do cuidado pessoal (GABRIEL, 2004). Assim como nas crianças, os envelhescentes e pessoas da terceira idade não podem se isolar do meio social em que vivem. Eles precisam ser participativos para alimentar as acepções cognitivas e metacognitivas dentro das suas ações na sociedade. E aprender uma língua estrangeira pode ser uma excelente estratégia para manter a atividade cognitiva e sócio pessoal desse público específico, a desafiar-se com novas atitudes de aprendizagem.

O envelhecimento traz declínio cognitivo pelo desgaste natural biológico da idade. Diante desse impacto, evidências em pesquisas sobre o bilinguismo mostram como é possível a obtenção de proteção contra o declínio cognitivo no envelhecimento.

Billig e Finger (2016) realizaram um estudo sobre a memória de trabalho de idosos e adultos, com a participação de 136 idosos bilíngues e monolíngues. Esse teste foi aplicado com o propósito de avaliar a preservação da memória de trabalho, manutenção e manipulação das ações e serve para medir o tempo dessas funções. Os resultados desse estudo revelaram que bilíngues e monolíngues se comportaram de maneira semelhante em termos de acurácia, mas os idosos bilíngues foram mais rápidos do que os idosos monolíngues. O exame dos resultados das tarefas executivas revelou menores custos cognitivos para os bilíngues, e, com isso, a diferença do desempenho entre adultos e idosos em termos de tempo de reação foi entre os bilíngues, sugerindo que o estudo de uma língua estrangeira esteja atuando como reserva cognitiva, retardando o impacto do envelhecimento.

Quanto mais subsídios se tiver sobre o processo de envelhecimento saudável, mais possibilidades teremos de evitar futuras demências, como também prevenir problemas cognitivos de demência neuronal e falta de cognição. Nessa faixa etária, os envelhescentes e pessoas da terceira idade apresentam menor velocidade de processamento da informação e precisam de maior disponibilidade de tempo para leitura e escrita em sala de aula, mas não impede que eles se motivem a reativar os neurônios e manter a sua cognição em equilíbrio.

\subsubsection{Leitura, cognição e envelhecimento}

No envelhecimento, algumas evidências de degeneração começam a surgir como a falta da acuidade visual, perda auditiva, demora para responder algu- 
mas perguntas, mas esses sinais evidentes são previstos para todos os envelhescentes. E, ainda que alguns traços de senilidade estejam presentes, como a falta de acuidade visual, as pessoas mais velhas demonstram interesse em permanecer com a habilidade de leitura, que é uma habilidade essencial para os envelhescentes e pessoas de terceira idade se manterem ativos socialmente no mundo letrado.

A leitura é uma atividade cognitivamente estimulante, pois o leitor passa a adquirir novas informações e ativar o cérebro continuamente. Nesse processo, os envelhescentes e pessoas da terceira idade exercitam, assim, as áreas neurocorticais, evitando as demências e ou perdas neurodegenerativas.

Assumimos a concepção de leitura proposta por Goodman (1967), para quem o leitor recodifica a codificação gráfica da fonética da língua, afirmando que o significado da palavra não é a parte principal da leitura a ser verbalizado oralmente, afirmando ainda ser possível essa verbalização, mas sem compreensão e que só poderá haver a compreensão da escrita do texto, se houver uma análise da decodificação da língua. (GOODMAN, 1967). No entanto, é possível que o leitor consiga efetuar dois procedimentos de leitura em dupla rota.

Do ponto de vista fisiológico, a leitura envolve diferentes estágios para o processamento da informação, com a transformação das informações recebidas pela visão e sistema de memória fonológica, até que sejam concluídas as compreensões do sistema semântico e sua finalização (LA BERGE; SAMUELS, 1974). Esses estágios envolvem dois níveis: acurácia e automaticidade.

No primeiro nível, denominado de acurácia, é necessário que o leitor esteja atento e concentrado para processar a compreensão da leitura. Já no nível de automaticidade, não se exige tanto a memória e a sua atenção por ser um processo de respostas automáticas em relação às perguntas recebidas; o leitor faz a leitura em um procedimento experimental e discorre as informações pelas tarefas adquiridas em dissociação.

A aquisição da decodificação das várias tarefas a serem feitas, leva-se muitos anos em que muitas pessoas não conseguem obter a fluência de um leitor fluente, mas mesmo assim, os leitores conseguem compreender melhor o desempenho de uma fala com facilidade e rapidez. (LA BERGE; SAMUELS, 1974, tradução nossa) ${ }^{4}$

\footnotetext{
4 “[...] The acquisition of the Reading skill takes years, and there are many who do not succeed in becoming fluent reader, even though they may have quickly and easily mastered the skill of understanding speech.”
} 
Durante a realização de uma tarefa cognitivamente complexa, como é a leitura, é necessário que sejam coordenados muitos componentes dos processos em um período curto de tempo. Se cada processo do componente da leitura necessitar de atenção, os desempenhos das tarefas complexas serão impossíveis de serem alcançadas. Mas se os componentes dessas tarefas forem ajustados, elas poderão ser processadas automaticamente, por isso os níveis de acurácia e automaticidade. Para chegar ao nível de automaticidade, é preciso ter consciência dos processos fisiológicos envolvidos na leitura.

Dehaene (2012) releva a importância da fisiologia da mecânica humana da leitura, relacionando cada leitor à sua forma de uso de estratégia para decodificar cada letra, palavra, frase. A leitura começa pelos olhos, mais especificamente pela retina, que é a responsável pela projeção dos fótons reenviados ao córtex cerebral através da fóvea, região central da retina. A fóvea corresponde a apenas $15^{\circ}$ do campo visual e é responsável pela captura da leitura, e, por sua característica estreita, faz com que os olhos se movam incessantemente no curso da leitura. A parafóvea corresponde ao ponto de fixação, em $5^{\circ}$ do padrão normal, e a região de fixação da leitura vai além da parafóvea (DEHAENE, 2012).

Os olhos fazem movimentos discretos e contínuos para captar a informação visual, o que corresponde à capacidade de decodificar entre quatro a cinco palavras por segundo. Por conta do grau de acuidade da fóvea e parafóvea, à medida que o campo leitor se afasta do centro do olhar, pode haver uma perda de codificação visual.

No nosso sistema de leitura do português, lemos da esquerda para a direita. O movimento captor ocular percorre as frases em sacadas (ou movimento sacádico), movimentos muito curtos e rápidos, que duram em torno de 30 a $50 \mathrm{~ms}$. As sacadas oculares correspondem ao número de letras percorridas no texto que podem ser variadas de acordo com o estilo da escrita. O número de caracteres que podemos executar em uma leitura é de aproximadamente entre sete e nove letras a cada sacada.

Nas fixações, os olhos fixam, com pausas entre sacadas; e duram em média de 200 a 250 ms. Nesse processo de sacadas e fixações, nem sempre o olhar segue palavra por palavra; Deheane (2012) afirma que palavras gramaticais, como verbos auxiliares, pronomes, conjunções, preposições ou artigos, são quase sempre puladas, e que as outras palavras essenciais de conteúdo, tais como nomes, verbos, adjetivos, advérbios, costumam ser fixadas pelo olhar.

Além das sacadas e fixações, existem os movimentos de retorno de leitura, quando os olhos movem do final da linha horizontal para o início da anterior ou da próxima linha, e a regressão de leitura, caracterizada por movimentos da 
direita para a esquerda, para regiões anteriores do texto na mesma linha ou para linhas anteriores (RAYNER; JUHASZ; POLLATSEK, 1998).

Leitores hábeis, ou no nível da automaticidade, fazem fixações mais curtas, sacadas mais longas, e menos regressões do que os leitores menos habilidosos, ou no nível da acurácia. Quando se trata de aprender a ler em uma língua estrangeira, é preciso ter o conhecimento gramatical para atingir a automaticidade nas fixações.

Ao traçarmos uma abordagem fisiológica da leitura, temos que considerar também os efeitos do envelhecimento nesse processo. O tempo de formação de um leitor é muito longo, o que equivale ao amadurecimento desde a primeira fase de criança, na alfabetização, até a adolescência, ao final da qual a estrutura corpórea fisiológica está amadurecida e o circuito neural está formado para executar todos os procedimentos de processamento de informação (LENT, 2005; DEHAENE, 2012).

Com o passar do tempo, as pessoas, de maneira geral, diminuem os ritmos de tarefas em todos os sentidos. Fisiologicamente, os músculos estão mais enrijecidos e tudo que fazemos é mais demorado. Na leitura, por exemplo, a retina está mais rígida, e com isso, a leitura, ao avançar da idade, começa a ficar mais lenta.

O monitoramento da leitura do movimento ocular propicia mensurar o tempo de duração das fixações e do movimento de retorno. Os olhos deslizam sempre da esquerda para a direita sobre o procedimento de leitura; na sacada, capturamos entre 7 a 9 caracteres; as pausas são sempre feitas e chamadas de fixações, as quais são sempre em torno de 200 a 250 ms, para leitura silenciosa, já na leitura em voz alta, o leitor executa as fixações em $275 \mathrm{~ms}$, para os leitores hábeis (RAYNER, CHACE, SLATTERY, ASHBY, 1998, p. 241-242). Como podemos ver, existe diferença entre a leitura em voz alta e a leitura silenciosa. Segundo Luegi, Costa e Faria (2006), a duração média das fixações na leitura silenciosa é de 250 ms, mesmo padrão estabelecido por Rayner et al. (1998), baseada no grau de dificuldades do leitor em relação a palavras isoladas ou frases. Em leitura em voz alta, os valores são modificados de acordo com os experimentos. A partir de experimento com a leitura de 2 textos por 20 participantes, as autoras identificaram os seguintes parâmetros: leitura em voz silenciosa $=225 \mathrm{~ms}$; e leitura em voz alta $=275 \mathrm{~ms}$. Esses dados se referem ao tempo de duração das fixações na leitura de textos em português de Portugal, aferidos pelo eye tracker 504 ASL scan path (LUEGI, COSTA, FARIA, 2006 p. 9).

Obter esse tipo de detalhamento sobre o processamento da leitura é importante para o planejamento de cursos e elaboração de materiais didáticos, a exemplo de ensinar uma língua estrangeira para envelhescentes e pessoas da terceira idade. 


\subsection{O TEMPO NA AULA DE INGLÊS}

Para verificar os efeitos do tempo cognitivo e do tempo social nas aulas de inglês, foram desenvolvidos três estudos: um estudo de leitura, um estudo sobre a organização do curso e um estudo de estados emocionais dos participantes. O primeiro estudo tem relação mais direta com o tempo cognitivo; os outros dois envolvem tanto o tempo cognitivo quanto o tempo social.

No estudo de leitura, quanto ao tempo, espera-se que os participantes sejam mais rápidos na leitura de textos em português do que em inglês, e também sejam mais rápidos na leitura silenciosa do que em voz alta. Quanto aos grupos experimentais, espera-se que os participantes mais jovens demandem menos tempo do que os participantes envelhescentes, que, por sua vez, demandem menos tempo do que os participantes idosos na execução dessas tarefas.

Quanto ao número de fixações na leitura, espera-se que os participantes do grupo experimental dos mais jovens façam menos fixações (com sacadas mais longas) do que os participantes envelhescentes, que, por sua vez, façam menos fixações do que os participantes idosos, em função das limitações fisiológicas do envelhecimento (enrijecimento da musculatura).

No estudo da organização do curso, relacionado ao tempo planejado e ao tempo executado de cada aula, considerando as evidências apontadas na literatura em relação à execução de tarefas e o dispêndio de tempo por parte dos idosos, espera-se que as aulas demandem mais tempo do que o planejado. Para identificar em que momentos há maior demanda de tempo, as aulas foram segmentadas em atividades e o tempo foi aferido para cada uma das atividades.

E, no estudo das emoções, foi desenvolvido um teste com fichas emocionais, que, considerando tratar-se de um curso livre, para participantes que não são obrigados a frequentá-lo (diferentemente de um público da faixa etária de escolarização obrigatória, por exemplo), espera-se que o estado emocional predominante seja positivo; o controle das emoções na entrada e na saída visa a identificar se o curso instiga mudanças emocionais em seus participantes.

O detalhamento dos estudos será apresentado na seção a seguir, assim como a apresentação do lócus do estudo: um curso de extensão de inglês para envelhescentes e pessoas de terceira idade. 